\title{
EPIDIDYMAL LIPID OF THE RAT WITH AND WITHOUT TESTICULAR CONTRIBUTION*
}

\author{
P. G. TURNER $\dagger$ AND A. D. JOHNSON \\ Animal Science Department, Livestock-Poultry Building, \\ University of Georgia, Athens, Georgia 30601, U.S.A.
}

(Received 1st December 1970)

\begin{abstract}
Summary. The efferent ducts of male rats were ligated and severed unilaterally to prevent passage of materials into the epididymis. The contralateral testis-epididymis complex served as control. Total lipid, free, total and esterified cholesterol, phospholipid and triglyceride were analysed on both contralateral control and isolated tissues at 1, 7, 14, 21, 28 and 35 days after surgery. Histological examination of the surgically isolated epididymides revealed the absence of spermatozoa in the caput at 1 day, corpus at 7 days and cauda at 21 days after surgery. With removal of spermatozoa from an area, lipid fractions tended generally to increase in concentration. Free cholesterol, as the percentage of cholesterol, was far lower than has been reported in the testis.
\end{abstract}

\section{INTRODUGTION}

Recent research has implicated the epididymis as a major source of substrates (Scott, Wales, Wallace \& White, 1963) which can support the metabolic activity of the maturing spermatozoon. Martan (1969) has suggested that the secretory product of the holocrine cells in the rat epididymis may be glycerylphosphorylcholine (GPG). Scott et al. (1963) proposed that GPC in the rat epididymis is formed from the phospholipids present in this organ, such as lecithin or choline plasmalogen.

As spermatozoa travel through the epididymis, they appear to undergo gross metabolic and composition changes. Typical of these changes is a decrease in palmitic acid in the phospholipid fraction and a drop in palmitic and linoleic levels and an increase in myristic and stearic levels in the neutral fraction (reviewed by Johnson, 1970). Mills \& Scott (1969) reported that the washed sperm cells of an ejaculate incorporated far less palmitic acid than testicular spermatozoa but oleic acid levels were relatively similar. Setchell, Scott, Voglmayr \& Waites (1969) reported a decrease in the phospholipid levels and cholesterol levels as spermatozoa pass through the epididymis.

These reports indicate metabolic activity in the epididymis, yet Montagna

* University of Georgia, College of Agriculture Experiment Stations, Journal Series, Paper No. 1048, College Station, Athens.

$\dagger$ Present address: American Breeder's Service, Inc., DeForest, Wisconsin. 
(1952) reported that by histochemical observations, demonstrable lipids and pigments are scant in the ductuli epididymides and that glycogen is limited to the basal cells. He confirmed the presence of carbohydrate metabolism, however, by finding the epithelial cells of the epididymis rich in acid phosphatase.

This study was undertaken to quantify various lipid fractions in epididymal tissue with and without contribution of spermatozoa and other constituents by the testis.

\section{MATERIALS AND METHODS}

Fifty-six mature male rats of the Wistar strain of similar age and weight were used as the experimental animals. These animals were given a standard diet of pelleted laboratory chow and water. Housing included a controlled environment with $12 \mathrm{hr}$ light/dark schedule. After initial surgery, these animals were not allowed to mate.

Anaesthesia was induced by ether and a testis-epididymal connection was severed through a mid ventral incision. The efferent ducts were ligated and then severed so that entrance from any source into the epididymis was impossible due to the ligature. This permitted the products of the testis to drain into the scrotum. The complex was then replaced and pushed slightly into the scrotum. This unilateral surgery was alternated from left to right sides and the contralateral complex served as control.

The surgical schedule was designed so that all animals were killed on the same day yielding tissues for lipid analysis and histology on Days 1, 7, 14, 21, 28 and 35 days after surgery. A total of four to eight animals was represented in a time period. Immediately after extraction, the tissues were either placed in a thin plastic bag and submerged in liquid nitrogen or placed in Bouin's solution.

Tissues were separated into testis and epididymis (caput, corpus or cauda) sections and subjected to lipid analysis after weighing. The lipid was extracted by grinding the tissue in chloroform-methanol (2:1) using a variation of the procedure of Folch, Lees \& Stanley (1957). Total lipid was determined by the weight of a dried extract aliquot as a percentage of the organ weight. Free and total cholesterol levels were determined by the procedures reported by Zak, Dickenman, White, Burnett \& Cherney (1954) and the esterified cholesterol fraction was represented by the difference between total and free levels. Phospholipid levels were determined by the procedure of Chen, Toribara \& Warner (1956). These values, representing inorganic phosphate, were converted to phospholipid by multiplying by 25 . Carboxyl ester was determined according to the procedure reported by Rapport \& Alonzo (1955) and from this, triglyceride levels were calculated according to the method of Fleeger, Bishop, Gomes \& VanDemark (1968). Fractions are referred to throughout on the basis of units per gram of wet tissue.

Histological specimens were fixed in Bouin's solution, dehydrated in various alcohol baths and embedded in paraffin. These tissues were then sectioned at 5 to $10 \mu \mathrm{m}$ and stained using a rapid haematoxylin-eosin procedure. Statistical differences were determined using Duncan's Multiple Range test (Steel \& Torrie, 1960). 


\section{RESULTS}

\section{Histology}

Plate 1 shows sections of control caput epididymidis (Fig. 1), corpus epididymidis (Fig. 3) and cauda epididymidis (Fig. 5) and isolated epididymal sections of the caput (Fig. 2), corpus (Fig. 4) and cauda (Fig. 6) at the time period when they were first found to be devoid of spermatozoa, i.e. 1, 7 and 21 days, respectively. Other factors such as tubule cell nuclei, maintenance of epithelial lining and condition of cilia and stereocilia appear normal. Tubular walls thickened considerably as their diameter decreased with their loss of contents. It appears, however, that cell number within the wall was unchanged. There appeared to be no effect due to the isolation on the morphology of the spermatozoa or epididymal cells.

\section{Organ weights}

The control testicular weights remained relatively stable $(1.38 \pm 0.09 \mathrm{~g})$. Following surgery (Day 1 ), isolated caput weights in the epididymis were less than two thirds of the control values, eventually diminishing $(P<0.05)$ to one fifth of the control weight (Table 1). Corpus weight compared to controls remained constant at all periods after surgery (Table 2). Cauda weights after surgery were comparable to controls until the organ became devoid of spermatozoa, at which time they diminished $(P<0.05)$ to one half the control value (Table 3).

\section{Total lipid}

The control total lipid value of $13 \cdot 2 \pm 2.4 \mathrm{mg} / \mathrm{g}$ wet weight of testis was the lowest of all the values for the organs analysed. The total lipid of the surgically isolated caput epididymidis rose $(P<0.05)$ after the tissue became free of sperm cells (Table 1$)$. The values for the surgically isolated corpus epididymidis tended to decrease initially, then rose $(P<0.05)$ and later declined $(P<0.05$; Table 2). The total lipid of the surgically isolated cauda epididymidis exhibited a general decrease $(P<0.05)$ after the organ became devoid of spermatozoa (Table 3 ).

\section{Cholesterol}

The values for total, free and esterified cholesterol for the control testis were $1.77 \pm 0.30,0.76 \pm 0.11$ and $1.02 \pm 0.17 \mathrm{mg} / \mathrm{g}$ wet weight, respectively. Total cholesterol values of the surgically isolated caput epididymidis rose $(P<0.05)$ above the control value after sperm loss, while free cholesterol values varied considerably from control values but in no noticeable pattern correlated with time after surgery or disappearance of spermatozoa. The esterified cholesterol values of the surgically isolated caput epididymidis rose $(P<0.05)$ significantly above the control one week after the disappearance of spermatozoa (Table 1). Total and esterified cholesterol values for the surgically isolated corpus epididymidis rose gradually above the control values until the disappearance of spermatozoa at which time there was a downward trend to values which were lower $(P<0.05)$ than the controls (Table 2$)$. Free cholesterol dropped $(P<0.05)$ initially but then rose $(P<0.05)$ after sperm removal. Total, free and esterified values of the surgically isolated cauda epididymidis increased $(P<0.05) 1$ week 

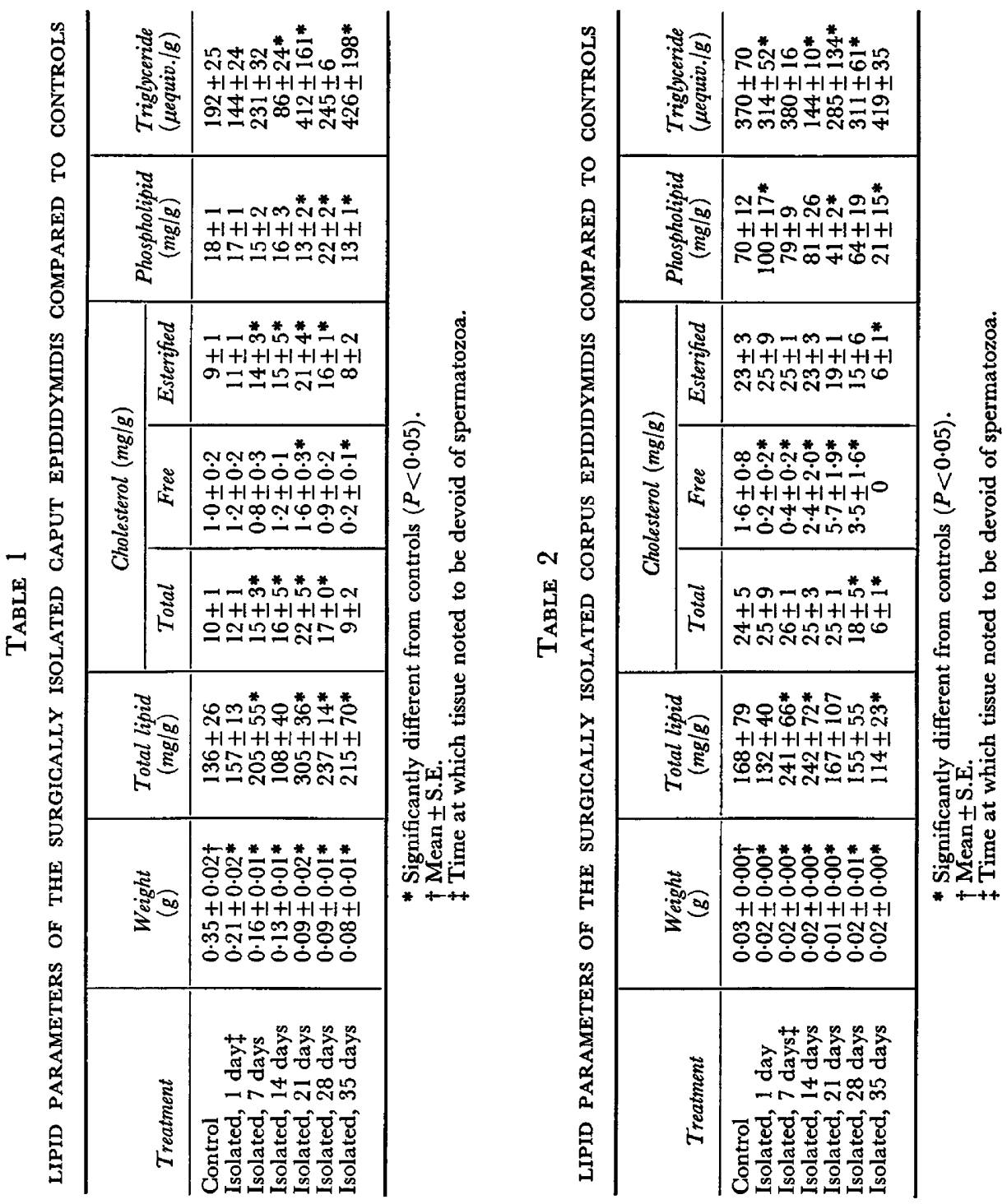


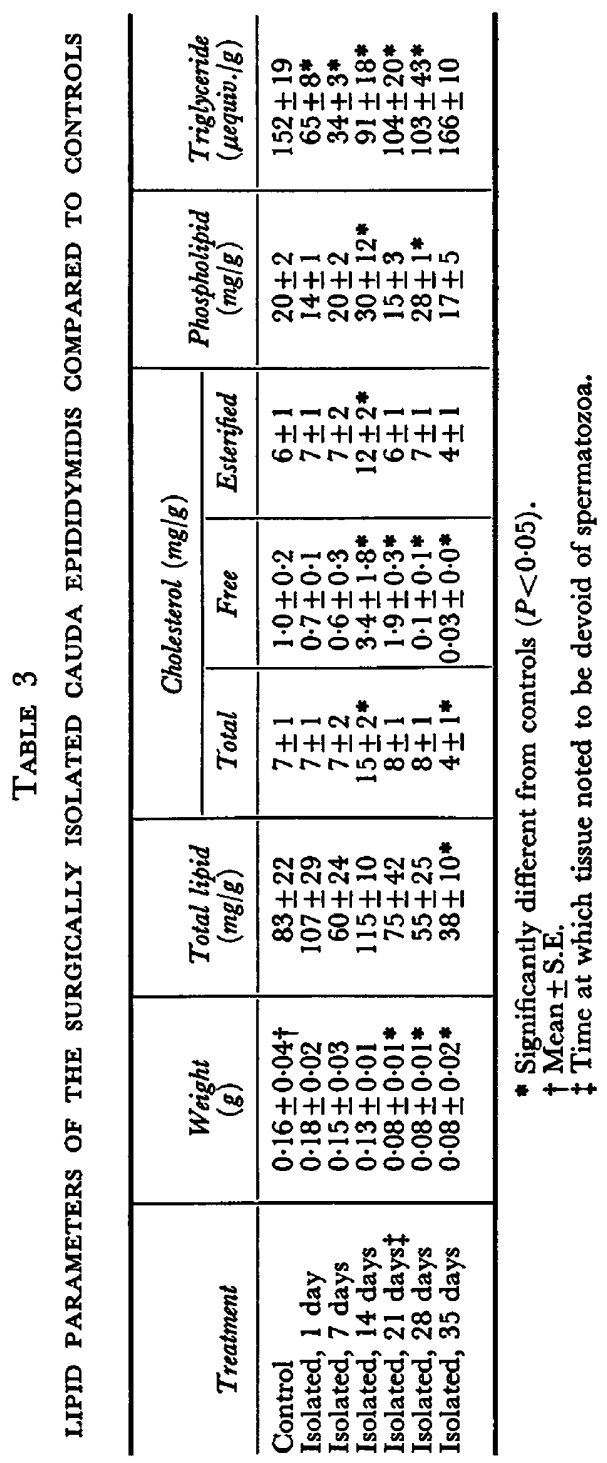


before the disappearance of spermatozoa from the organ and then decreased $(P<0.05$; Table 3$)$.

\section{Phospholipid}

The phospholipid value for the control testis was $6.28 \pm 0.48 \mathrm{mg} / \mathrm{g}$ while epididymal values were much higher, particularly for the control corpus. There were no prominent trends for phospholipid values for the surgically isolated caput, corpus and cauda epididymidis which could be associated with time or disappearance of spermatozoa.

\section{Triglyceride}

The control testis had the lowest triglyceride value of all the organs examined $(6.92 \pm 1.35 \mu$ equiv. $/ g)$. The triglyceride values for the surgically isolated caput epididymidis after the spermatozoa left the organ ( 1 day after surgery) were generally higher than the control values (Table 1). As shown in Table 2, triglyceride values for the surgically isolated corpus epididymidis declined 1 week after the organ was noted to be devoid of spermatozoa ( 7 days after surgery). In the surgically isolated cauda epididymidis, triglyceride values dropped $(P<0.05)$ immediately following surgery until 14 days after surgery, when the values started to rise to control levels (Table 3 ).

\section{DISCUSSION}

From this study, it appears that the spermatozoa and fluid from the testis which is contained within the caput and cauda epididymidis constitute a major part of the weight. Since the weight of the corpus epididymidis did not appreciably decline with the loss of spermatozoa, it appears that in this portion of the organ the spermatozoa constitute a small portion of the weight.

The lipid fraction values for the testis in this study in general appear to be lower than some of the previously reported values for the rat (see review by Johnson, 1970). A comparison of the epididymal lipid values found in this study with those of the testis indicates that the epididymis contains far more lipid than the testis. However, since the epididymis has a higher percentage dry weight than the testis, these values in this study appear to be within a range

\section{EXPLANATION OF PLATE 1}

Fig. 1. Contralateral control caput epididymidis of the tissue shown in Fig. 2. The tubules contain large numbers of sperm cells and appear to be distended with fluid.

Frg. 2. Caput epididymidis which was surgically isolated 1 day previously by ligation and severing of the efferent ducts. Spermatozoa are almost completely absent and the tubules are decreased in size.

FIG. 3. Contralateral control corpus epididymidis (compare with Fig. 4).

FrG. 4. Gorpus epididymidis isolated surgically 7 days previously. The tubules are devoid of sperm cells and are smaller than in the contralateral control (Fig. 3).

Fig. 5. Gauda epididimydis contralateral control containing a heavy concentration of sperm cells in distended tubules (compare with Fig. 6).

Frg. 6. Cauda epididymidis which was isolated surgically 21 days previously. Tubules are essentially devoid of sperm cells and are much smaller than when the spermatozoa were present as seen in Fig. 5. 
PLATE 1

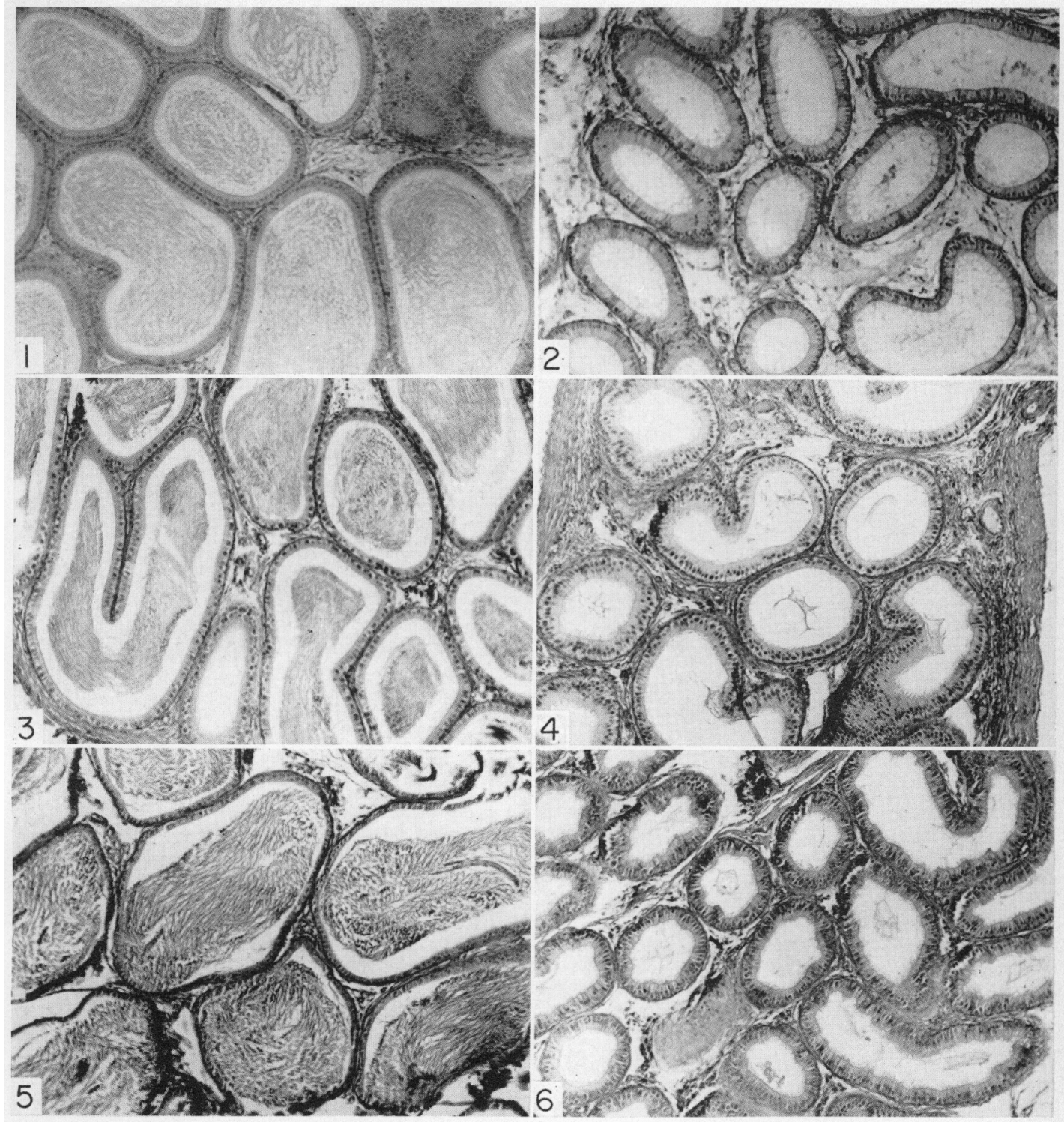

Photomicrographs of the rat epididymis. Tissues were fixed in Bouin's solution and stained by a rapid hacmatoxylin-cosin method $(\times 67)$. 
which is certainly higher than those of the testis but not as great as the values appear to be on a wet weight basis.

It appears that in general the lipid fractions tend to increase as the particular portion of the organ becomes devoid of spermatozoa and testicular fluid. This has been shown to occur in the testis as the germinal elements are damaged or are removed from the tissue (see review by Johnson, 1970). In the testis, these changes are much more dramatic, however, suggesting that the loss of spermatozoa has less to do with these changes than do the pre-spermatozoal germ cells. The levels of the triglyceride fractions have been shown to be lower in the ejaculated spermatozoa than in total testis tissue, while total lipid, cholesterol and phospholipid tend to be higher (review by Johnson, 1970). In the epididy$\mathrm{mis}$, the rise in certain fractions as the spermatozoa leave a particular portion may be due either to failure of the spermatozoa to utilize these constituents, thus allowing their accumulation, or to removal of spermatozoa and fluids, contributed by the testis, which contain a level of these constituents lower than the tissue of the epididymis.

\section{REFERENGES}

Ghen, P. S., Toribara, T. Y. \& Warner, H. (1956) Microdetermination of phosphorus. Analyt. Chem. $28,1756$.

Fleeger, J. L., Bishop, J. P., Gomes, W. R. \& VanDemark, N. L. (1968) Testicular lipids. I. Effect of unilateral cryptorchidism on lipid classes. 7. Reprod. Fert. 15, 1.

Folch, J., Lees, M. \& Stanley, G. H. S. (1957). A simple method for the isolation and purification of total lipids from animal tissues. F. biol. Chem. 226, 497.

Johnson, A. D. (1970) Testicular lipids. In: The Testis. II. Biochemistry. Eds. A. D. Johnson, W. R. Gomes and N. L. VanDemark. Academic Press, New York.

Martan, J. (1969) Epididymal histochemistry and physiology. Biol. Reprod. 1, 134.

MirLs, S. C. \& ScotT, T. W. (1969) Metabolism of fatty acids by testicular and ejaculated ram spermatozoa. F. Reprod. Fert. 18, 367.

Montagna, W. (1952) Some cytochemical observations on human testes and epididymides. Ann. N.Y. Acad. Sci. 55, 629.

Rapport, M. M. \& Alonzo, N. (1955) Photometric determination of fatty acid ester groups in phospholipids. F. biol. Chem. $217,193$.

Scott, T. W., Wales, R. G., Wallace, J. G. \& White, I. G. (1963) Gomposition of ram epididymal and testicular fluid and the biosynthesis of glycerylphosphorylcholine by the rabbit epididymis. 7. Reprod. Fert. 6, 49.

Setchell, B. P., Scott, T. W., Voglmayr, J. K. \& Wattes, G. M. H. (1969) Characteristics of testicular spermatozoa and the fluid which transports them into the epididymis. Biol. Reprod. 1, 40.

Steel, R. G. D. \& Torrie, J. H. (1960) Principles and procedures of statistics. McGraw-Hill, New York.

Zak, B., Dickenman, R. G., White, E. G., Burnett, H. \& Gherney, P. J. (1954) Rapid estimation of free and total cholesterol (modification No. 2). Am. F. clin. Path. 24, 1307. 